\title{
RNANÇAS
}

\section{Mercado de capitais}

mercado de capitais éuma das formas que pode assumir a intermediação financeira, ou troca de recursos entre agentes no sistema capital ista. Sua final idade é garantir a capitalização das empresas, ao mesmo tempo em que proporciona retornos atraentes a seus investidores. Este artigo analisa o mercado de capitais brasileiro, apresentando e discutindo as razões de seu atual baixo dinamismo e formas de superá-lo.

Por Fernanda F. C. Perobelli FEA-UFJF

No sistema capitalista, a intermediação financeira, ou troca de recursos entre os agentes, desenvolve-se de forma segmentada em quatro tipos de mercados: o mercado monetário, no qual ocorrem transações com títulos de curtíssimo prazo; o mercado de crédito, representado pelas operações de financiamento de curto e médio pra- zos, direcionadas aos ativos permanentes e/ou capital de giro das empresas e ao crédito direto ao consumidor; 0 mercado de câmbio, formado por operações de troca de moeda entre agentes credenciados para tal e, de especial interesse neste artigo, o mercado de capitais.

0 mercado de capitais, representado pelas Bolsas de 
Valores e mercados de balcão organizados, contempla as operações com valores mobiliários de médio e longo prazos, como ações, debêntures, commercial papers, bônus de subscrição. Seu objetivo é proporcionar liquidez aos títulos de propriedade e de dívida de emissão das empresas e viabilizar seu processo de capitalização.

Muitos dos investimentos dessas empresas requerem volumes expressivos de recursos, que serão aplicados a prazos longos, envolvendo considerável grau de risco. 0 mercado de capitais, portanto, tem como missão adicional tornar esses investimentos líquidos e, conseqüentemente, menos arriscados e mais atraentes aos investidores.

Mas, para que isso ocorra, esse mercado tem de atender aos interesses de seus dois participantes: as empresas, que necessitam de financiadores para seus projetos, eosinvestidores, que esperam obter retornos justos pelo capital aportado às empresas. O bviamente, caso al gum desses participantes não tenha interesse em estar no mercado de capitais, as Bolsas de Valores e mercados de balcão organizados não atingirão um grau de eficiência satisfatório: ou porque não há ofertantes de títulos no mercado, ou porque não há demandantes.
Nosso propósito, neste artigo, édiscutir quais as principais razões para o baixo dinamismo ea reduzida eficiência do mercado de capitais, especificamente o brasileiro. Para tanto, analisamos, em um primeiro momento, os principais fatores envolvidos com o lado da oferta de títulos pelas empresas e, em um segundo, as características próprias desse mercado que o tornam pouco atraente para empresas e investidores no Brasil. Por fim, o artigo propõe algumas medidas para elevar a eficiência do mercado de capitais brasileiro.

O Iado da oferta. Pelo lado da oferta de títulos pelas empresas no mercado de capitais, diferentes teorias desenvolvidas ao longo dos últimos 40 anos sugerem que as empresas podem selecionar sua estrutura de capital, isto é, a combinação entre emissão de dívida e ações, de acordo com determinados atributos teóricos relevantes.

A influência de tais atributos sobre a decisão de financiamento derivaria dos impactos que estes seriam capazes de exercer sobre os custos e ben efícios associados à emissão de ações ou de dívida, podendo ser resumidos, como se segue, a oito principais.

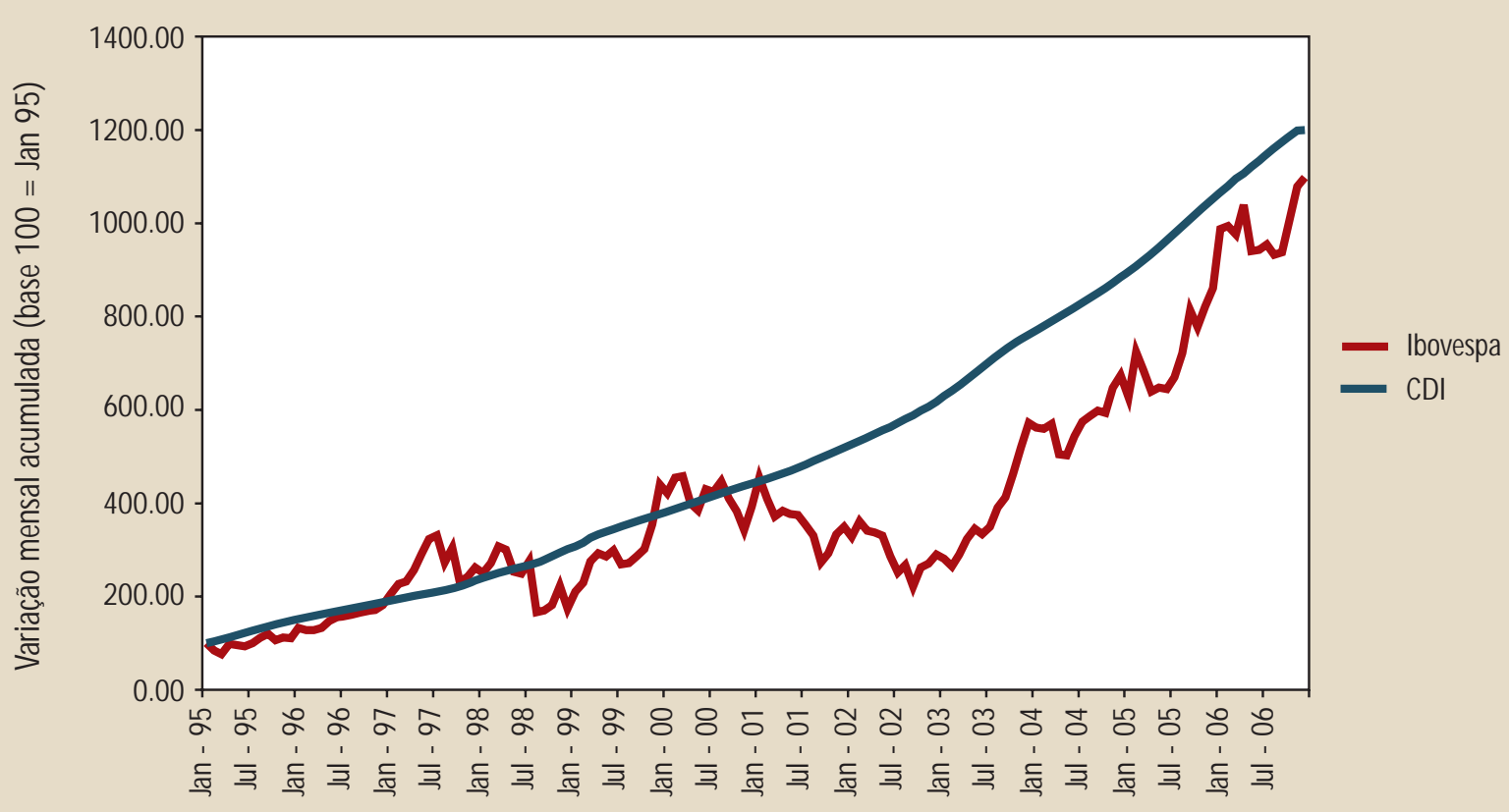

Gráfico 1 - Comparativo Ibovespa-DI.

Fonte: Economática. Elaboração própria. 
O primeiro atributo é a estrutura dos ativos e sua tangibilidade. De acordo com isso, empresas com maior volume de ativos tangíveis, que podem ser usados como garantia, reduzindo custo do endividamento, tenderiam a preferir endividar-se. 0 segundo refere-se aos atributos fiscais extradívida, de acordo com os quais a existência de deduções fiscais adicionais, como as advindas da depreciação, por exemplo, competindo pela mesma base de tributação (lucros), deveria diminuir o apetite das empresas pelo endividamento, se o objetivo desse fosse unicamente reduzir o lucro tributável.

Em terceiro lugar está o atributo da expectativa de crescimento. Empresas com muitas oportunidades rentáveis disponíveis, ou seja, com elevada expectativa de crescimento, tenderiam a endividar-se menos, por serem vistas como mais arriscadas pelos credores. 0 quarto atributo é chamado de singularidade: empresas que comercializem produtos muito singulares ou de difícil substituição tenderiam a sofrer grandes perdas em seu valor de mercado residual em caso de falência e, por isso, tenderiam a endividar-se menos.
Já o quinto atributo éo tamanho. Estudos têm sugerido que empresas maiores possuiriam menor probabilidade de falência e, por isso, sua capacidade de endividamento seria superior à das empresas de menor porte. 0 sexto atributo é a volatilidade. Deacordo com ele, empresas que apresentam menor volatilidade em seus resultad os deveriam ser menos propensas a dificuldades financeiras, o que tornaria mais barato o custo do endividamento e, portanto, as tornaria mais propensas à contração de dívidas.

0 sétimo atributo éa lucratividade. De acordo com uma teoria conhecida como pecking order, empresas operando em mercados pouco transparentes adotariam uma ordem de prioridadepara aescol ha das fontes de financiamento. Em primeiro lugar, estariam os lucros retidos; a seguir, o endividamento e, por fim, a emissão de novas ações, dado que essa última forma poderia ser mal interpretada pelos acionistas (empresas emitiriam novas ações quando acreditassem queo valor dessas estivesse sobrevalorizado, mas nunca quando acreditasse que estivesse subvalorizado). N este contexto, empresas com alta lucratividade deveriam ser menos endividadas, ao mesmo tempo em que fariam menos ofertas de ações.

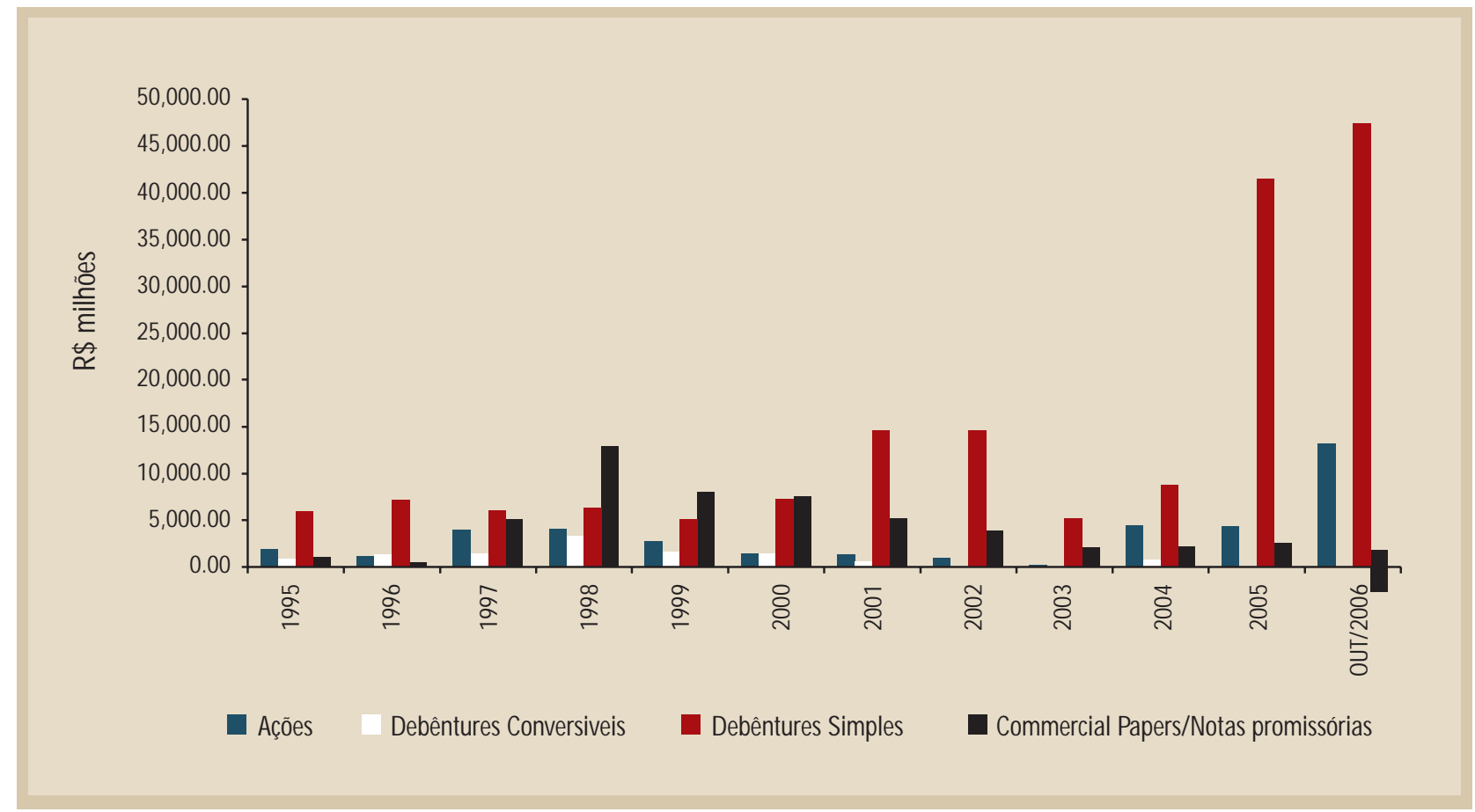

Gráfico 2 - Brasil: Mercado primário por tipo de título emitido. Fonte: CVM. 
Governança corporativa. Por último, o oitavo atributo diz respeito à qualidade da governança corporativa. Diferentes argumentos justificam a inclusão desse atributo entre os possíveis determinantes da estrutura de capital das empresas. Pesquisas recentes argumentam que, em mercados com baixa proteção aos investidores minoritários e pouca transparência, os investidores aplicariam um desconto generalizado no valor das ações ofertadas pelas empresas de forma a garantir que estariam pagando por elas um valor justo.

Supõe-se, nesse caso, que os referidos investidores não possam julgar de forma correta quais são as ações de melhor qualidade. Como conseqüência, ações de empresas com boa governança seriam compradas com deságio em relação a seu valor justo, enquanto ações de empresas com governança ruim seriam compradas por seu valor correto ou até mesmo com ágio.

A assimetria informacional criaria, portanto, um problema de seleção adversa, ao desestimular a oferta de ações por empresas com boa governança e ao estimular a oferta de ações por empresas com governança ruim em mercados pouco transparentes. Nos mercados com baixa proteção aos acionistas minoritários, como no caso do brasileiro, não restaria outra saída às empresas com boas práticas de governança a não ser buscar outras fontes de financiamento, entre elas o endividamento, induzindo uma relação positiva entre qual idade da governança corporativa e grau de endividamento.

Baixo di namismo. Vamos agora analisar algumas características do mercado de capitais brasileiro que o tornam pouco atraente ou que explicam seu baixo dinamismo. Duas características podem ser real çadas: primeira, os al tos custos diretos eindiretos do mercado de capitais, eisso tanto para as empresas como também para os investidores; e, segunda, a falta de proteção aos interesses de acionistas minoritários. No restante deste artigo, em específico, analisaremos apenas a primeira característica.

Sabe-se que a emissão pública de títulos e a manutenção da condição de companhia aberta não são isentas de custos diretos. Relatório divulgado pela Bovespa em seu site apresenta os custos diretos da abertura de capital e da

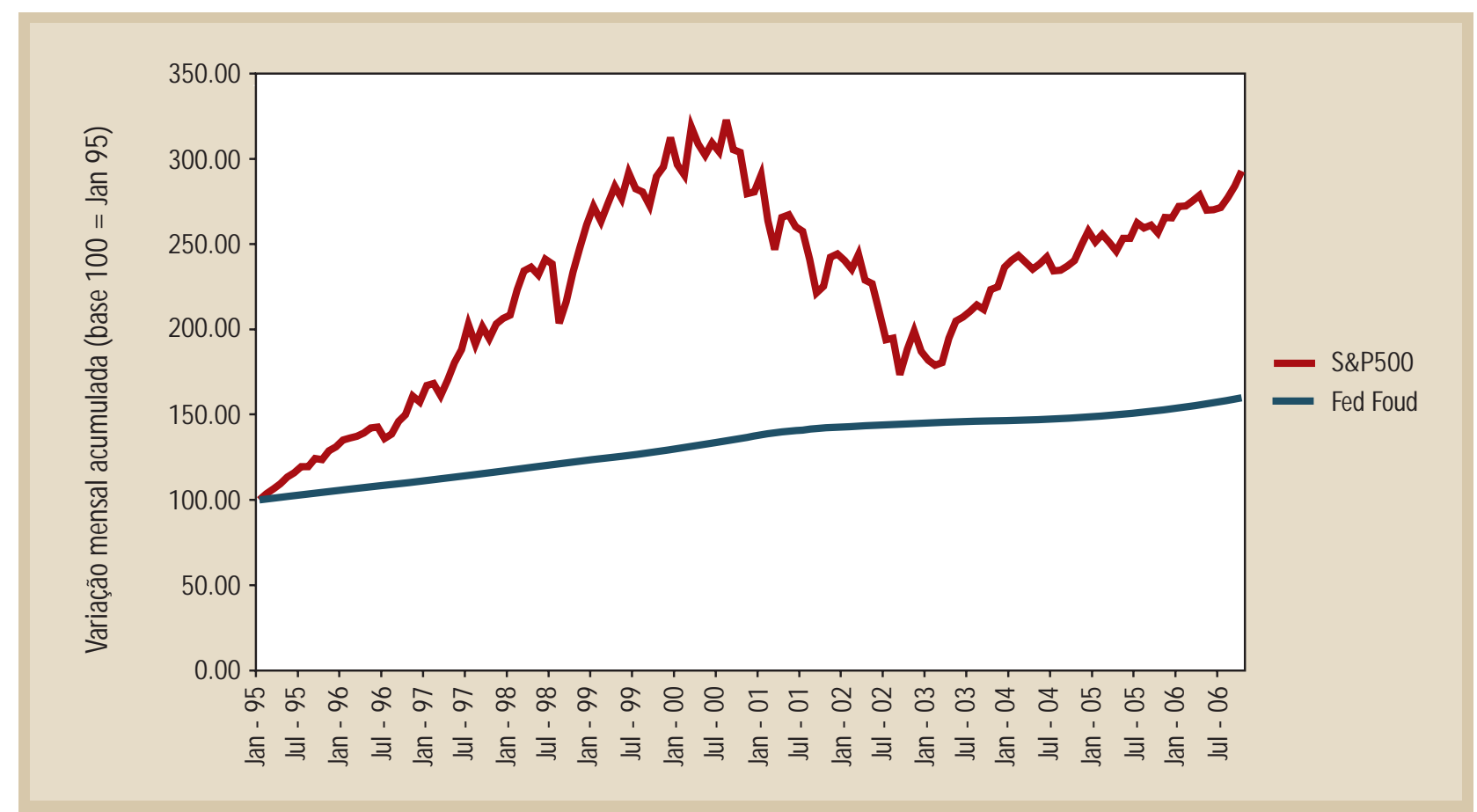

Gráfico 3 - Comparativo S\&P500-Fed Funds.

Fonte: Economática. Elaboração própria. 
manuten ção da condição de companhia aberta. Mas para o investidor também há custos diretos: a cobrança de taxas e do imposto de renda sobre ganhos de capital são exemplos de custos diretos.

No entanto, para nossos propósitos aqui, mais relevantes do que os custos diretos são os custos indiretos do investimento no mercado de capitais. Para os investidores, esses são representados pela pouca liquidez de algumas ações e de quase a totalidade dos títulos de dívida (debêntures e commercial papers) e pelo custo de oportunidade do investimento em ações.

Com vistas ao combate à inflação, o país nos últimos anos apresentou taxas de crescimento econômico declinantes, com queda na produção das empresas e taxas de juros reais em patamares el evados, que provocaram uma migração dos recursos do setor privado para o setor público ao tornar o mercado acionário pouco atraente para o investidor brasileiro quando comparado ao mercado de taxas de juros.

De forma a evidenciar a discrepância entre as taxas de retorno nos dois mercados, considere um investidor que tivesse, em 2 de janeiro de 1995, adquirido a carteira teórica do Índice Bovespa (Ibovespa) vigente naquela data. Caso esse investidor tivesse mantido esse investimento até 4 de dezembro de 2006, o retorno obtido por ele no período seria de $998 \%$. Se o mesmo investidor tivesse aplicado em títulos que rendessem $100 \%$ do CDI, o retorno obtido seria de $1.100 \%$, ou seja, superior ao obtido no mercado acionário.

Esses números mostram que títulos considerados livres de risco ofereceram ao investidor, nosúltimos 12 anos, uma taxa de retorno mais elevada que as ações de empresas, que carregam um risco maior. Dessa forma, ao se tentar calcular o prêmio de risco para a carteira de ações mais líquidas do mercado brasileiro, chegar-se-ia a um prêmio pelo risco negativo, revelando que o investidor avesso ao risco estaria, na verdade, pagando um prêmio para assumir o risco adicional. Essa contradição é evidenciada pelo Gráfico 1.

Custos para as empresas. Para as empresas, os custos indiretos da emissão de ações e de títulos de dívida podem ser mais claramente expostos observando-se as Teorias de Estrutura de Capital. As principais teorias acerca do assunto indicam que o perfil da empresa parece ser determinante na decisão de financiamento: empresas start-ups (baixa rentabilidade, curto histórico, geralmente associado a alto potencial de crescimento) e empresas que detêm um al to volume de ativos intangíveis ou comercializam produtos altamente especializados geralmente enfrentam custos menores promovendo a emissão de ações.

As empresas maduras capazes de colocar seus títulos de dívida no mercado a taxas atraentes remunerariam melhor seus acionistas se optassem pelo endividamento. Os benefícios do endividamento são advindos de alguns fatores. Primeiro, do efeito al avancagem do capital próprio menor capital investido e apropriação, pelos acionistas, da diferença entre o retorno operacional do empreendimento e a taxa de juros paga aos credores. Segundo, do benefício fiscal do endividamento - despesas financeiras são isentas de tributação no Brasil.

Um terceiro fator éa eliminação dos custos de agência da emissão de ações - deságio por assimetria de informação/baixa transparência e do underpricing. Considerado um dos mais sérios obstáculos à abertura de capital via ações, este fenômeno, constatado em vários países, faz com que as ações sejam ofertadas a um preço em média inferior ao preço de fechamento no primeiro dia em que a ação é transacionada.

Várias teorias sugerem que o underpricing é natural, pois os agentes que vendem as ações possuem informação superior à dos investidores que as compram. Assim sendo, o underpricing aparece como um prêmio que investidores exigem para transacionar com agentes com informação superior. As teorias traçam, portanto, um quadro ideal para o financiamento das empresas, de acordo com seu ciclo de vida, representado na Figura 1.

As empresas brasileiras participantes do mercado de capitais, as mais atuantes sendo ainda as de grande portee em estágio de maturidade, observam tais questões quando de seu financiamento. De acordo com o que pode ser observado no Gráfico 2, percebe-se que as emissões de títulos de dívida (debêntures e commercial papers) superaram as ofertas primárias de ações (incluindo ofertas públicas iniciais e colocações secundárias) nos últimos dez anos.

Alternativas à vista. 0 que fazer, diante das evidências anteriormente apresentadas, para elevar o dinamismo do mercado de capitais brasileiro? Em nossa perspectiva, 
uma solução pode ser aventada se esse mercado conseguir ofertar o produto certo para o cliente certo. Em específico, identificamos duas situações.

Primeiro, é preciso haver um mercado de ações eficiente para empresas que estão no momento de start-up, de preferência aderente aos padrões de boa governança corporativa, de forma a diminuir o deságio sofrido nas colocações, devendo inclusive os reguladores desse mercado incentivar e fomentar iniciativas relacionadas à formação de um mercado ativo de capital de risco (venture capital), estágio preliminar às ofertas iniciais de ações na maioria dos mercados de capitais desenvolvidos.

Segundo, épreciso haver um mercado detítulos dedívida padronizado, transparente e líquido para empresas maduras. Isso porque, pelo lado da oferta, como foi discutido, épouco provável que empresas maduras (como Vale do Rio Doce e Petrobrás, empresas quehádez anos, pelo menos, não realizam uma subscrição deações) decidam utilizar o mercado acionário como instrumento de captação. Ao contrário do que prega o senso comum, a emissão de dívida é muito mais viável para essas empresas do que a emissão de ações.

Em contrapartida, empresas com alto potencial de crescimento em setores ainda não consolidad os e empresas que detêm um al to volume de ativos intangíveis, ou comercializam produtos altamente especializados, enfrentariam custos menores promovendo a emissão de ações.

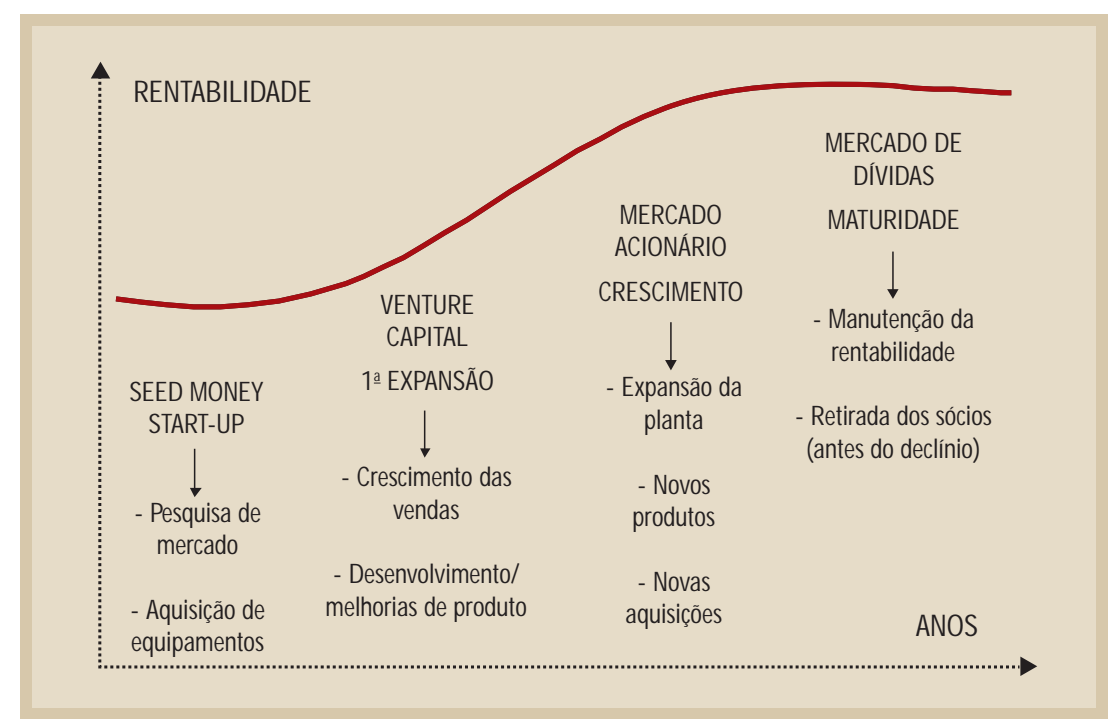

Figura 1 - Relação entre tipo de financiamento e ciclo de vida da empresa. Fonte: Securato (2005).
N este ponto, o leitor poderia questionar por que a solução sugerida para o mercado de capitais brasileiro parece ser o estímulo também ao mercado de títulos de dívida, enquanto, no mercado norte-americano, benchmark quando se trata de mercado de capitais, são as ações as grandes estrelas. Apesar de não haver respostas precisas a essa pergunta, algumas conjecturas podem ser levantadas.

Em primeiro lugar, pelo lado da demanda (investidores), a tendência de crescimento da economia norte-americana, verificada nos últimos anos, provocou uma elevação nos preços das ações, não enfraquecida pelas modestas elevações nas taxas de juros norte-americanas, precisamente o contrário do verificado no mercado brasileiro, conforme se observa no Gráfico 3.

Em segundo lugar, poderia ser argumentado que há razões culturais: os norte-americanos negociam ações desde a "mania das ferrovias", ocorrida ao final do século XVIII. A New York Stock Exchange (NYSE) data de 1792. Já no Brasil, a capacidade de poupança das famílias brasileiras e a convivência com regimes inflacionários explosivos foram fatores que retardaram o acesso do investidor brasileiro médio ao mercado de ações.

Pelo lado da oferta, formado pelas empresas, o mercado acionário nos Estados Unidos é contemporâneo das grandes empresas norte-americanas, enquanto, no Brasil, os planos de desenvolvimento econômico adotados financiaram a maioria das atuais grandes empresas brasileiras, desestimulando a busca de recursos no mercado de ações. É bom lembrar que as bolsas brasileiras começaram a operar em meados da década de 1960, com ofertas modestas de parte do capital detido pelo Governo nas empresas estatais. Nesse sentido, há ainda um longo caminho a ser percorrido pela Bolsa de Valores no Brasil até sua maturidade alocativa.

Fernanda F. C. Perobelli

Doutora em Administração pela FEA-USP Profa. da FEA-UFJF

E-mail: ffinotti@labfin.com.br 